\title{
Residual stresses in deep-drawn cups made of duplex stainless steel X2CrNiN23-4
}

\section{Influence of the drawing depth}

\author{
Nicola Simon ${ }^{1}$ (D) $\cdot$ Hannes Erdle ${ }^{2} \cdot$ Stefan Walzer $^{3} \cdot$ Jens Gibmeier ${ }^{1} \cdot$ Thomas Böhlke $^{2} \cdot$ Mathias Liewald $^{3}$
}

Received: 19 January 2021 / Accepted: 27 May 2021 / Published online: 28 June 2021

(c) The Author(s) 2021

\section{Abstract}

Residual stress development in deep drawing processes is investigated based on cylindrical cups made of duplex stainless steel sheet. Using a two-scale approach combining finite element modelling with a mean field homogenization scheme the macro residual stresses as well as the phase-specific micro residual stresses regarding the phases ferrite and austenite are calculated for steel $\mathrm{X} 2 \mathrm{CrNiN} 23-4$ for various drawing depths. The simulation approach allows for the numerical efficient prediction of the macro and phase-specific micro residual stress in every integration point of the entire component. The simulation results are validated by means of X-ray diffraction residual stress analysis applied to a deep-drawn cup manufactured using corresponding process parameters. The results clearly indicate that the fast simulation approach is well suited for the numerical prediction of residual stresses induced by deep drawing for the two-phase duplex steel; the numerical results are in good agreement with the experimental data. Regarding the investigated process, a significant influence of the drawing depth, in particular on the evolution of the residual stress distribution in drawing direction, is observed. Considering the appropriate phase-specific strain hardening, the two-scale approach is also well suited for the prediction of phase specific residual stresses on the component level.

Nicola Simon

nicola.simon@kit.edu

1 Institute for Applied Materials (IAM), Karlsruhe Institute of Technology (KIT), Karlsruhe, Germany
2 Institute of Engineering Mechanics (ITM), Karlsruhe Institute of Technology (KIT), Karlsruhe, Germany

3 Institute for Metal Forming Technology (IFU), University of Stuttgart, Stuttgart, Germany 


\section{Eigenspannungen in tiefgezogenen Rundnäpfen aus Duplex-EdelstahI X2CrNiN23-4}

Einfluss der Ziehtiefe

\section{Zusammenfassung}

In dieser Arbeit wird die Eigenspannungsentwicklung bei Tiefziehprozessen anhand von Rundnäpfen aus dem DuplexEdelstahlblech X2CrNiN23-4 untersucht. Unter Verwendung eines Zwei-Skalen-Ansatzes, der eine Finite-Elemente-Modellierung mit einem Mean-Field-Homogenisierungsschema kombiniert, werden die Makroeigenspannungen sowie die phasenspezifischen Mikroeigenspannungen bezüglich der Phasen Ferrit und Austenit für unterschiedliche Ziehtiefen berechnet. Der Simulationsansatz ermöglicht die numerisch effiziente Vorhersage der Makro- und phasenspezifischen Mikroeigenspannungen in jedem Integrationspunkt des gesamten Bauteils. Die Simulationsergebnisse werden anhand von röntgenographischen Eigenspannungsanalysen validiert, die an einem mit entsprechenden Prozessparametern hergestellten tiefgezogenen Napf durchgeführt wurden. Die Ergebnisse zeigen deutlich, dass der schnelle Simulationsansatz für die numerische Vorhersage der durch das Tiefziehen induzierten Eigenspannungen für den grob zweiphasigen Duplexstahl gut geeignet ist; die numerischen Ergebnisse sind in guter Übereinstimmung mit den experimentellen Daten. In Bezug auf den untersuchten Prozess wurde ein signifikanter Einfluss der Ziehtiefe, insbesondere auf die Entwicklung der Eigenspannungsverteilung in Ziehrichtung, festgestellt. Unter Berücksichtigung der entsprechenden phasenspezifischen Verfestigung ist der Zwei-Skalen-Ansatz auch für die Vorhersage von phasenspezifischen Eigenspannungen auf Bauteilebene gut geeignet.

\section{Introduction}

Deep drawing is a well-established and frequently used sheet metal forming process for manufacturing structural components. Prior to the large-scale production of a new component, the drawing process usually is optimized regarding sheet thinning [1] and reduced distortion after spring back [2, 3]. Significant residual stresses, which are frequently neglected during the assessment of sheet forming processes, develop during the forming process [4], that may affect the components behaviour in service [5]. Considering or utilizing these residual stresses, for example via targeted induced compressive residual stresses at predominantly tensile stressed areas, may reduce the superimposed acting stresses and can counteract crack initiation. By this means, the components lifetime can be significantly increased.
Hence, regarding the components production process, this enables the use of reduced metal sheet thickness to fulfill the ever increasing light-weight requirements and reduces material costs at the same time.

Numerical methods, such as finite element method (FEM), nowadays allow for fast and precise simulation of the forming process and thereby the prediction of the resulting residual stress distribution [6]. Simulative approaches provide powerful tools for efficient and targeted optimization of production processes without elaborate experimental tests, provided that the material behaviour is modeled precisely. In sheet metal forming, multiphase materials, such as dual phase and duplex stainless steels are frequently used since they perfectly meet the requirements for deep drawn components, that is, these materials combine high strength and good ductility and in case of the duplex stainless steels

Fig. 1 Deep Drawing tool for manufacturing of cylindrical cups with a diameter of $100 \mathrm{~mm}$ (left), Process description of the deep drawing process $(\mathbf{a}-\mathbf{c})$, manufactured cylindrical cup of $40 \mathrm{~mm}$ drawing depth (d)
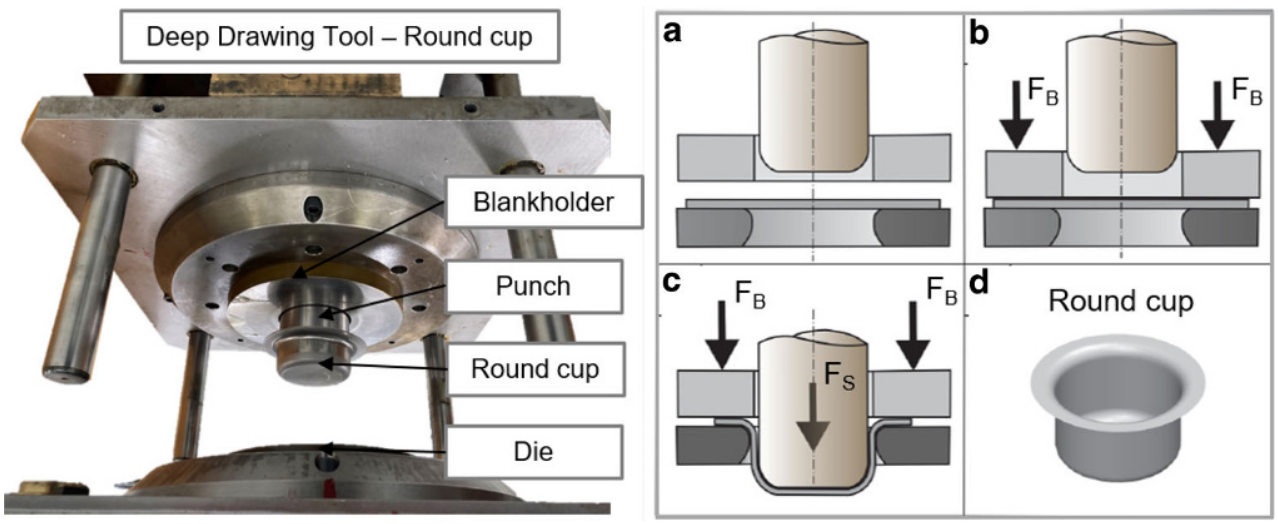

Table 1 Chemical composition of X2CrNiN23-4 in weight-\% [11]

\begin{tabular}{lllllllll}
\hline $\mathrm{C}$ & $\mathrm{Cr}$ & $\mathrm{Ni}$ & $\mathrm{Mn}$ & $\mathrm{Co}$ & $\mathrm{Si}$ & $\mathrm{Mo}$ & $\mathrm{N}$ & $\mathrm{Fe}$ \\
\hline 0.034 & 23.91 & 4.74 & 1.326 & 0.104 & 0.38 & 0.37 & 0.13 & Balance \\
\hline
\end{tabular}



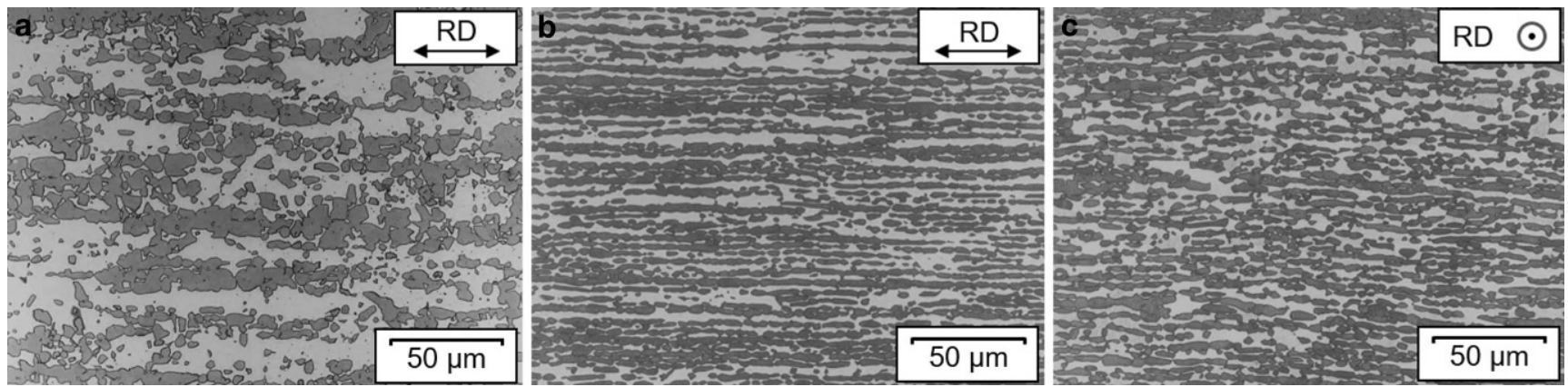

Fig. 2 Microstructure of cold rolled X2CrNiN23-4 sheets for planar section (left), longitudinal cross section (centre) and transverse cross section (right): ferrite (bright phase) and austenite (dark phase) [9]

Fig. 3 Anisotropy of the cold rolled $\mathrm{X} 2 \mathrm{CrNiN} 23-4$ sheet: crystallographic texture given by inverse pole figures for the phases austenite and ferrite, referred to the sheet normal direction (left) and macroscopic anisotropy given by tensile tests for three orientations in plane including the Ludwik-Hollomon approximation of the strain hardening used for numerical simulation (right)

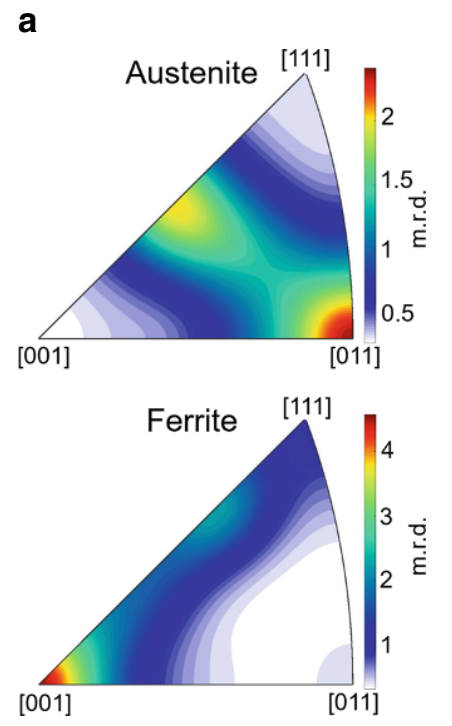

b

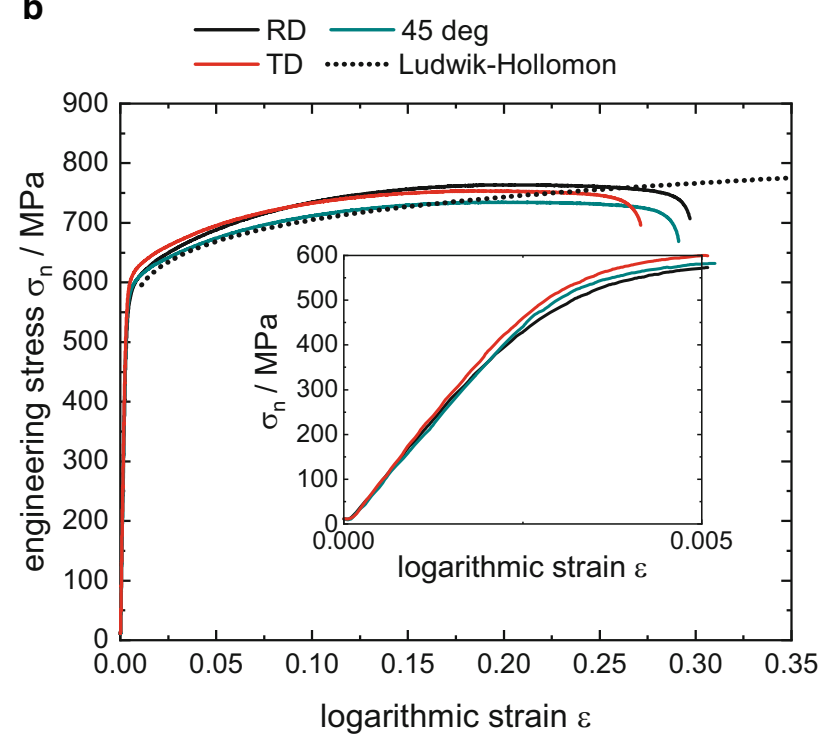

This work focuses on the residual stress evolution in sheet metal forming of duplex stainless steel $\mathrm{X} 2 \mathrm{CrNiN} 23-4$, consisting of ferrite and austenite phases in equal volume fraction. Here, the mean field homogenization is used as a numerically efficient method for the simulation of residual stress on the phase level during the simulation of structural parts. As a result of the sheet rolling process, both phases possess significant crystallographic textures, which must be taken into account and bring additional challenges for precise experimental analysis and numerical simulation of residual stress. To meet these challenges, elaborate approaches from the fields of technical mechanics, metal sheet processing and materials testing are combined within an interdisciplinary cooperation. In [9], a numerically efficient two-step simulation approach for the prediction of phase-specific residual stresses is developed. In a first step finite-element simulations are performed to predict the macroscopic stress and strain states. Based on the finite-element results a mean-field homogenization scheme is used in a second step to estimate the phase-specific residual stresses. In [10] an incremental two-scale simulation 
Table 2 Anisotropic material properties of the cold rolled $\mathrm{X} 2 \mathrm{CrNiN} 23-4$ steel sheet

\begin{tabular}{lllll}
\hline$\alpha$ & $E_{\alpha}$ & $R_{p 0.2, \alpha}$ & $R_{m, \alpha}$ & $r_{\alpha}$ \\
\hline $0^{\circ}$ & $196 \mathrm{GPa}$ & $568 \mathrm{MPa}$ & $762 \mathrm{MPa}$ & 0.59 \\
$45^{\circ}$ & $193 \mathrm{GPa}$ & $582 \mathrm{MPa}$ & $737 \mathrm{MPa}$ & 0.72 \\
$90^{\circ}$ & $204 \mathrm{GPa}$ & $597 \mathrm{MPa}$ & $754 \mathrm{MPa}$ & 0.78 \\
\hline
\end{tabular}

approach is presented, which allows for the consideration of the history of phase-specific micro residual stress evolution for complex forming processes. With the phase-specific and anisotropic strain hardening of the duplex stainless steel X2CrNiN23-4 investigated in [11], the mean field approach can now be applied for sheet metal forming simulation considering the anisotropic and phase-specific material behaviour. In this work, the influence of the drawing depth of circular deep drawn cups made of duplex stainless steel $\mathrm{X} 2 \mathrm{CrNiN23-4}$ on the residual stress distribution is investigated. The mean field approach is applied for prediction of the global macro and phase-specific micro residual stress distribution for three different drawing depths. For validation of the numerical results, a deep drawn cup made of duplex stainless steel $\mathrm{X} 2 \mathrm{CrNiN} 23-4$ was manufactured with dimensions that correspond with the simulation. The numerical results are validated by experimentally determined residual stress distributions that were analyzed by means of X-ray diffraction for multiple measuring points along the cup's wall. With this work, it is aimed to contribute to the understanding of residual stress generation during deep drawing processes, especially for duplex stainless steels.

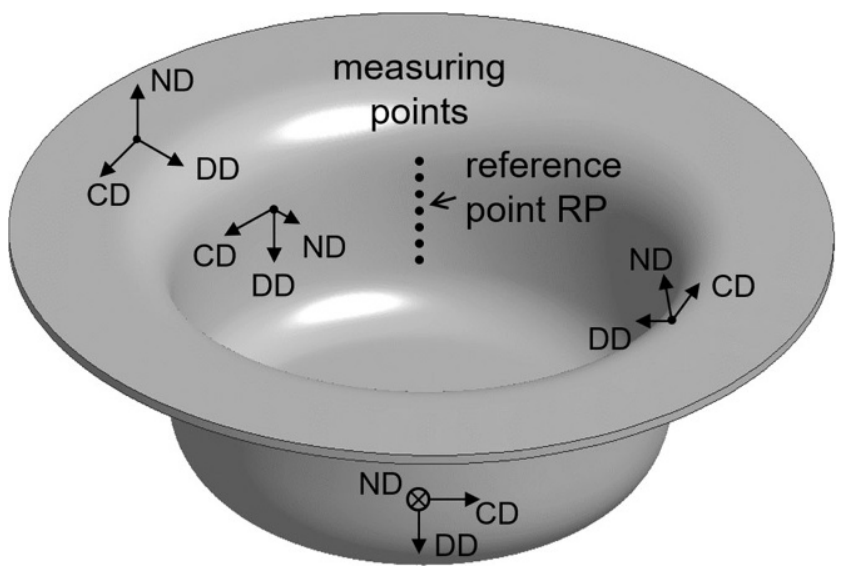

Fig. 4 Schematic visualization of measuring points at the inside wall considered for X-ray residual stress analysis and specifying of the applied local coordinate systems with circumferential direction (CD), drawing direction (DD) and normal direction (ND)

\section{Experimental}

\subsection{Processing}

Fig. 1 schematically shows the process principle of deep drawing using the cylindrical cup investigated in this study. The rigid deep drawing tools consist of the tool components punch, die and blank holder (see Fig. 1, left) [12]. Duplex stainless steel blank of $\mathrm{X} 2 \mathrm{CrNiN} 23-4$ with a thickness of $1.5 \mathrm{~mm}$ and a blank diameter of $180 \mathrm{~mm}$ were used for the deep drawing experiments on a deep drawing press type NST S2-6300(D)-Servo from AIDA Europe GmbH.

During deep drawing, the blank holder is the first, which closes after the insertion of the sheet metal blank (see Fig. 1b). Afterwards the sheet metal is clamped between the die and the blank holder with the blank holder force $F_{\mathrm{B}}=180 \mathrm{kN}$. As soon as the punch hits the sheet metal blank and applies the force required for forming, the material flows predominantly out of the sheet thickness [13]. The blank holder force reduces the flow of the sheet metal during the drawing process and thus controls the sheet metal draw-in from the flange area between die and blank holder (Fig. 1c). When immersed in the blank, the punch clamps the sheet metal over the die radius and forms it into the die. The punch force $F_{\mathrm{B}}$ required for forming increases continuously up to the lower dead centre of the tool-kinematic. The sheet metal blanks were wetted on both sides with deep drawing lubricant during the experiments.

\subsection{Material}

Duplex stainless steel sheet of type X2CrNiN23-4 (AISI S32304) with sheet thickness of $1.5 \mathrm{~mm}$ was used for the experiments in the as-received state, i.e. cold rolled with surface finish type $2 \mathrm{~B}$. The manufacturing process included a cold rolling process, a heat treatment at $1100^{\circ} \mathrm{C}$ followed by quenching in compressed air and water, pickling and a final skim pass rolling. The material consists of the phases austenite $(\gamma)$ and ferrite $(\alpha)$ in equal volume fractions. The chemical composition, given in Fig. 1 was analyzed using emission spectroscopy and melt extraction.

The phase-specific crystallographic texture was determined by means of X-ray diffraction, as described in [11]. Three incomplete pole figures were analyzed at the sheet surface for both phases, respectively. Using the open source Matlab toolbox MTEX, inverse pole figures were calculated for ferrite (body centered cubic structure - bcc) and austenite (face centered cubic structure - fcc), as depicted in Fig. 3. Obviously, both phases show different but characteristic crystallographic textures.

For analysis of the macroscopic anisotropy, multiple tensile tests have been performed in rolling direction, transverse direction and $45^{\circ}$-direction. Despite the presented 
Table 3 Material parameters of austenite and ferrite for mean-field modeling based on experimental results of Simon et al. [11]

\begin{tabular}{llllll}
\hline & $E_{\alpha, \nu}$ & $\mu_{\alpha, \gamma}$ & $\sigma_{\alpha, \gamma}^{\mathrm{F}}$ & $m_{\alpha, \gamma}$ & $\varepsilon_{\alpha, \gamma}^{0}$ \\
\hline Austenite & $190 \mathrm{GPa}$ & 0.31 & $420 \mathrm{MPa}$ & 6 & 0.002 \\
Ferrite & $202 \mathrm{GPa}$ & 0.288 & $380 \mathrm{MPa}$ & 11 & 0.002 \\
\hline
\end{tabular}

phase-specific crystallographic texture, the cold rolled material possesses only minor differences in orientation-depending macro mechanical properties as can be seen in Fig. 3. The Young's modulus $E_{\alpha}$, Yield point $R_{p 0.2, \alpha}$, ultimate strength $R_{m, \alpha}$ and Lankford parameter $r_{\alpha}$ are given in Fig. 2, referred to the angular orientation $\alpha$ to the sheet rolling direction. The listed values reflect averages from three tensile tests per orientation.

\subsection{Experimental residual stress analysis}

The deep drawn cup with highest drawing depth, i.e. $40 \mathrm{~mm}$, was chosen for experimental validation of the numerical results using X-ray stress analysis according to the well known $\sin ^{2} \psi$-method [14]. The cup was formed as described in Fig. 2.1 and subsequently cut to avoid shadowing effects (shadowing of the X-ray beam path by the cup) and allow for residual stress measurements at the inner surface of the cup's wall. The material removal was reduced to the necessary minimum to avoid significant residual stress redistributions. Repeated residual stress analyses at an accessible measuring point on the outer wall before and after sectioning showed a difference of less than $10 \%$. In order to analyse the lateral residual stress gradient, seven measurement points with $2 \mathrm{~mm}$ distance to each other were defined over the cup's wall on a path along the transverse direction in respect of the initial cold rolled sheet, as shown in Fig. 4. The middle measuring point of this path is chosen as reference point RP and was located at the cup's half height. RP was chosen as point of reference in the presentation of the results.
A 4-circle $\Theta-2 \Theta$-diffractometer in combination with V-filtered $\mathrm{Cr}-\mathrm{K} \alpha$ radiation was used for residual stress analysis. On the primary beam path side a $1 \mathrm{~mm}$-pinhole collimator was applied. In front of the scintillation detector a $4 \mathrm{~mm}$ symmetrization slit [15] and $2 \mathrm{~mm}$-single slit aperture were used for analysis of the $\{211\}$-ferrite and the $\{220\}$ austenite diffraction lines, respectively. After linear background correction, the interference lines were fitted using a Pearson VII function. Thereby, the $\mathrm{K} \alpha_{2}\{220\}$-diffraction line was considered via a double-peak fit. 15 tilt angles $\psi$ equally distributed over $\sin ^{2} \psi$ were set, with limitation of $|\psi| \leq 50^{\circ}$, to avoid shadowing effects from the curved wall of the sectioned deep drawn cup. For stress evaluation, lattice plane specific diffraction elastic constants for ferrite $\frac{1}{2} s_{2}^{\{211\}}=5.7006 \times 10^{-6} \mathrm{MPa}^{-1}$ and austenite $\frac{1}{2} s_{2}^{\{220\}}=5.9613 \times 10^{-6} \mathrm{MPa}^{-1}$ were used [11]. For all measuring points, the residual stress components in circumferential direction (CD) and drawing direction (DD) were analyzed for both phases $\left\langle\sigma_{\mathrm{CD}, \mathrm{DD}}\right\rangle^{\alpha, \gamma}$. From these phasespecific stresses, the macro residual stresses $\sigma_{\mathrm{CD}, \mathrm{DD}}$ and phase-specific micro residual stresses $\left\langle\sigma_{\mathrm{CD} D \mathrm{DD}}^{I I}\right)^{\alpha, \gamma}$ were calculated under consideration of the phase volume fraction $c_{\alpha, \gamma}$ using the following equations [16]:

$\sigma_{\mathrm{CD}, \mathrm{DD}}=c_{\alpha}\left\langle\sigma_{\mathrm{CD}, \mathrm{DD}}\right\rangle^{\alpha}+c_{\gamma}\left\langle\sigma_{\mathrm{CD}, \mathrm{DD}}\right\rangle^{\gamma}, c_{\alpha}+c_{\gamma}=1$

$\left\langle\sigma_{\mathrm{CD}, \mathrm{DD}}^{I I}\right\rangle^{\alpha, \gamma}=\left\langle\sigma_{\mathrm{CD}, \mathrm{DD}}\right\rangle^{\alpha, \gamma}-\sigma_{\mathrm{CD}, \mathrm{DD}}$

\section{Numerical simulation}

The numerical simulation of the phase-specific residual stresses is performed in a two step approach introduced in
Fig. 5 Global macro residual stress distributions in circumferential direction CD (left) and drawing direction DD (right) for drawing depth $d=40 \mathrm{~mm}$ a

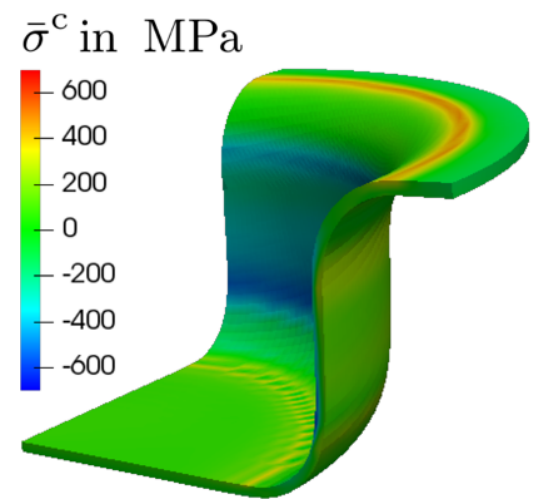

b

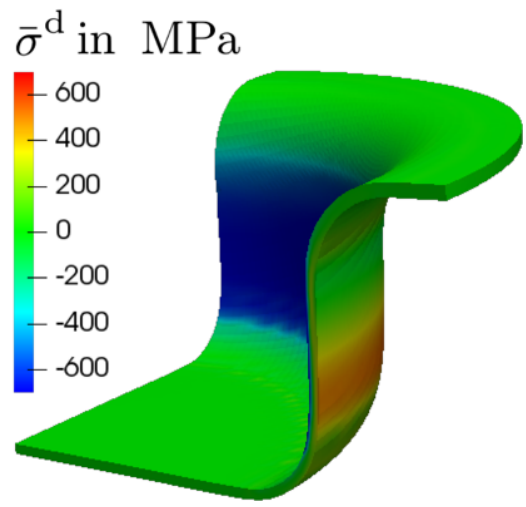


Fig. 6 Global micro residual stress distributions in circumferential direction (index ' $c$ ') (left) and drawing direction (index 'd') (right) for drawing depth $d=40 \mathrm{~mm}$ : austenite ' $\gamma$ ' (top) and ferrite ' $\alpha$ ' (bottom) a

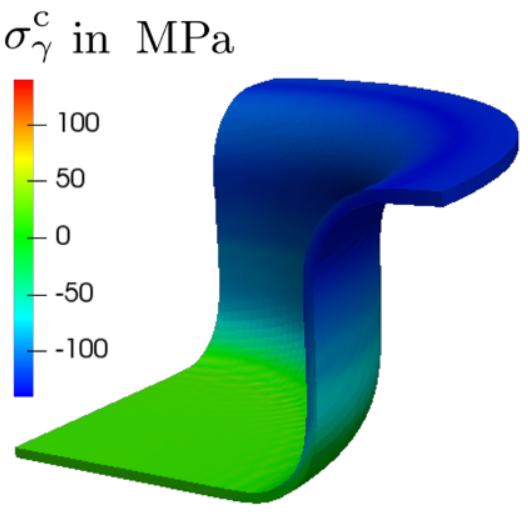

C

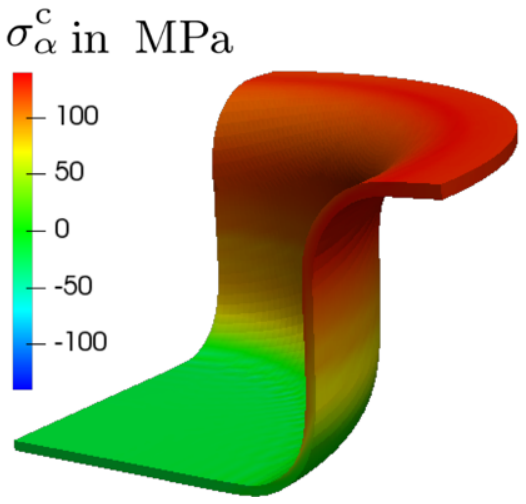

b

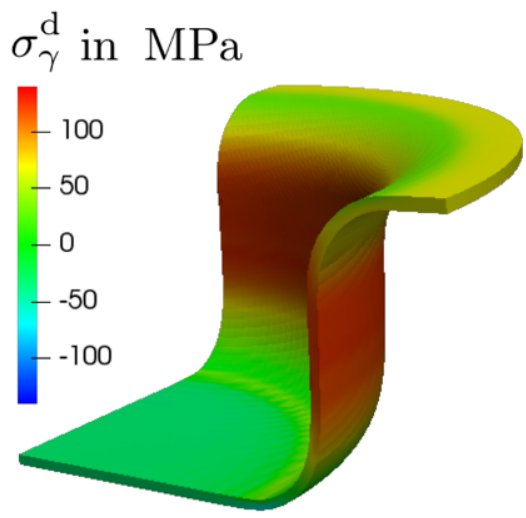

d

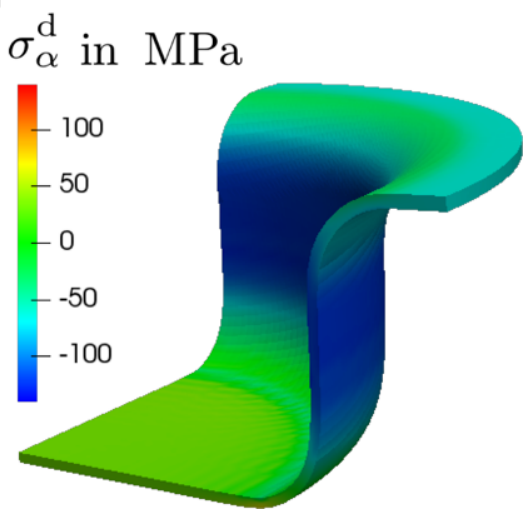

Simon et al. [9]. In the first step, the macroscopic residual stress distribution is calculated by a finite-element modeling using Abaqus Standard by Dassault Systèmes. The resulting effective stress and strain states before and after unloading are used as an input for the micromechanical mean-field modeling. Hereby, steady phase-specific plastic strains are assumed during the unloading step.

The macroscopic elasto-plastic material response is characterized experimentally by tensile tests in rolling direction $\left(0^{\circ}\right)$, in $45^{\circ}$ to the rolling direction and in transverse direction $\left(90^{\circ}\right.$ ) (see Fig. 3). For simplicity, the macroscopic elastic behavior is modeled isotropic with Young's modulus $E=195 \mathrm{GPa}$ and Poisson ratio $v=0.3$. The Ludwik-Hollomon approach is chosen for the evolution of the flow stress $\sigma_{\mathrm{F}}\left(\varepsilon_{\mathrm{p}}\right)=a \varepsilon_{\mathrm{p}}^{n}$ with the equivalent plastic strain $\varepsilon_{\mathrm{p}}(t)=\int_{0}^{t}\left\|\dot{\varepsilon}_{\mathrm{p}} \widetilde{(t)}\right\| \widetilde{\mathrm{d} t}$ and material parameters $a$ and $n$. Based on the results of the tensile tests the parameters of the Ludwik-Hollomon approach are chosen as $a=840 \mathrm{MPa}$ and $n=0.076$. The approximated strain hardening is visualized in Fig. 3.

The anisotropic behavior of the material is taken into account according to the Hill yield criterion based on the determined $r$-values listed in Table 2.

The simulation setup of the deep drawing process up to drawing depths of $20 \mathrm{~mm}, 30 \mathrm{~mm}$ and $40 \mathrm{~mm}$ is as follows.
One quarter of the sheet metal blank is modeled with 34310 eight-node brick elements (C3D8), where an element number of 10 over the blank thickness of $s_{0}=1.5 \mathrm{~mm}$ is used. The coefficient of friction between the blank and a tool surfaces is chosen as $\mu=0.1$. In correspondence with the experiment a blank holder force of $F_{\mathrm{B}}=180 \mathrm{kN}$ is applied.

The macroscopic simulation gives the effective stress $\overline{\boldsymbol{\sigma}}$, the effective strain $\overline{\boldsymbol{\varepsilon}}$ and the effective plastic strain $\overline{\boldsymbol{\varepsilon}}_{\mathrm{p}}$ for the loaded state as well as after the unloading step. The corresponding quantities on the microscale of the material are given point-wise by localization relations with the 4th-order strain localization tensor $\mathbb{A}(\boldsymbol{x})$, the 4 th-order stress localization tensor $\mathrm{B}(\boldsymbol{x})$ and the corresponding strain and stress fluctuation fields $\boldsymbol{a}(\boldsymbol{x})$ and $\boldsymbol{b}(\boldsymbol{x})$. Averaging over a phase $\xi$ it follows for the strain and stress within the phase $\boldsymbol{\varepsilon}_{\xi}=\mathbb{A}_{\xi}[\overline{\boldsymbol{\varepsilon}}]-\boldsymbol{a}_{\xi}$ and $\boldsymbol{\sigma}_{\xi}=\mathbb{B}_{\xi}[\overline{\boldsymbol{\sigma}}]-\boldsymbol{b}_{\xi}$. As shown in [9, $10]$, for a two phase material, i.e., $\xi=1,2$, explicit expressions are given for the localization tensors and fluctuation fields based on the phase volume fractions $c_{\xi}$, the effective stiffness tensor $\overline{\mathbb{C}}$, the phase-specific stiffness tensors $\mathbb{C}_{\xi}$ and the plastic strains within the phases $\boldsymbol{\varepsilon}_{\mathrm{p} \xi}$. Backstress effects are not considered in the present work due to the lack of data for non-proportional loading histories.

For simplicity, the microstructure of the material is assumed to be statistically isotropic, which allows the char- 
a

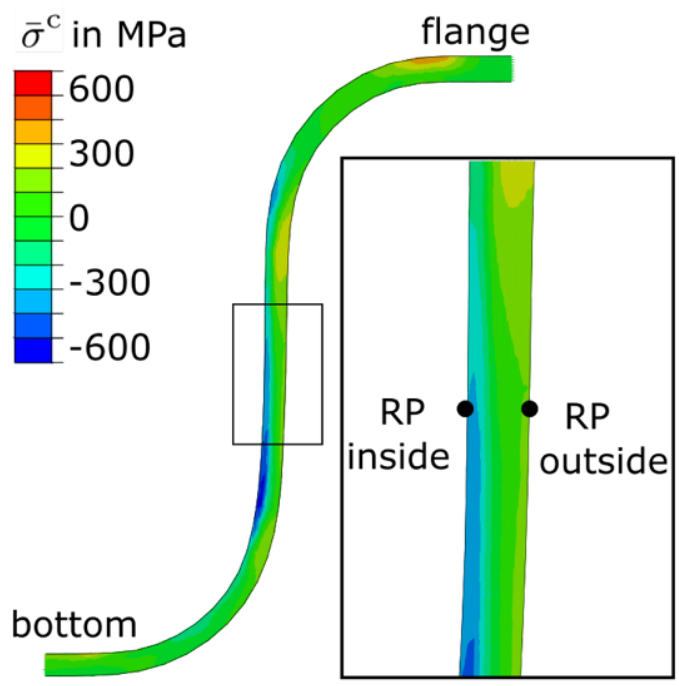

b

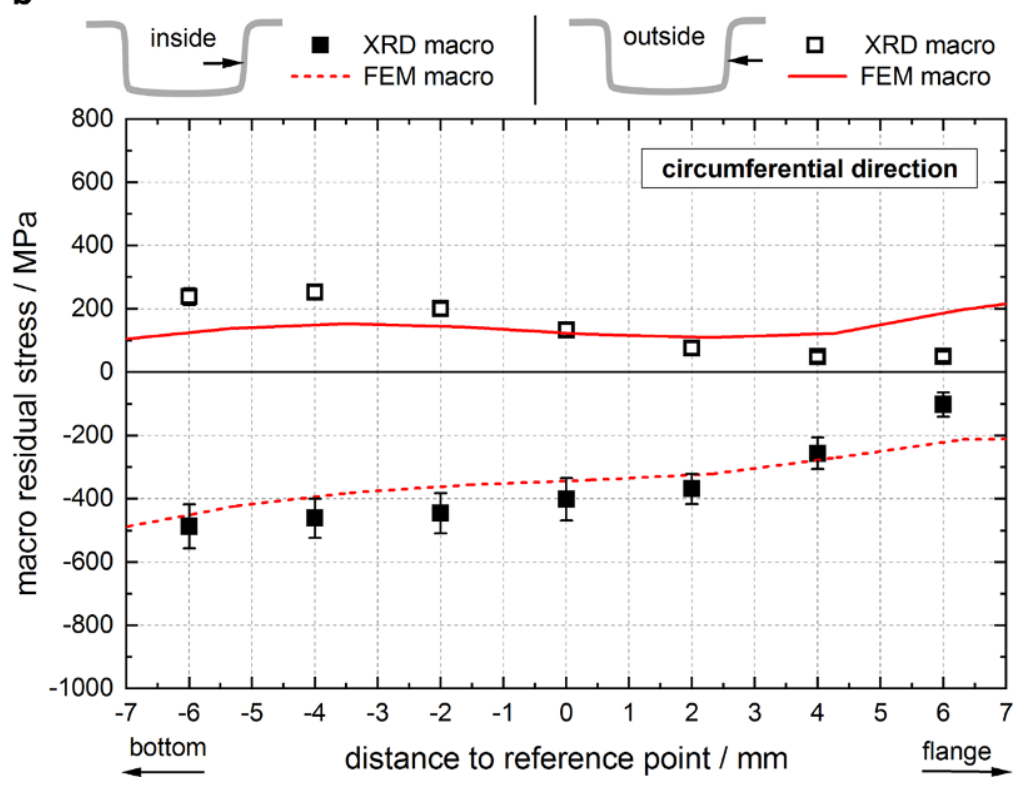

Fig. 7 Macro residual stress distribution in circumferential direction (index 'c') at the cup's wall for $d=40 \mathrm{~mm}$ : FEM results (left) and validation with XRD results (right). At the contour plot the location of the reference point RP is given; the enlarged image section corresponds to a height of $14 \mathrm{~mm}$

acterization of the phase-specific stiffness tensors by the Young's modulus $E_{\xi}$ and the Poisson ratio $v_{\xi}$. Furthermore, it is assumed that both for the effective material behavior as well as for the phase averages the incremental form Hooke's law is valid, i.e. $\Delta \overline{\boldsymbol{\sigma}}=\overline{\mathbb{C}}\left[\Delta \overline{\boldsymbol{\varepsilon}}-\Delta \overline{\boldsymbol{\varepsilon}}_{\mathrm{p}}\right]$ and $\Delta \boldsymbol{\sigma}_{\xi}=\mathbb{C}_{\xi}\left[\Delta \boldsymbol{\varepsilon}_{\xi}-\Delta \boldsymbol{\varepsilon}_{\mathrm{p} \xi}\right]$. This allows the usage of the small strain homogenization scheme within an objective incremental setting of large deformations. For details on the incremental two-scale material modeling it is referred to Hofinger et al. [10]. In this work the phase-specific plastic strains are given by the generalized Ramberg-Osgood relation

$\boldsymbol{\varepsilon}_{\mathrm{p} \xi}=\varepsilon_{\xi}^{0}\left(\frac{\sqrt{\frac{2}{3}}\left\|\boldsymbol{\sigma}_{\xi}^{\prime}\right\|}{\sigma_{\xi}^{\mathrm{F}}}\right)^{m_{\xi}} \frac{\boldsymbol{\sigma}_{\xi}^{\prime}}{\left\|\boldsymbol{\sigma}_{\xi}^{\prime}\right\|}$,

which accounts for multiaxial stress states. Hereby, the reference strain $\varepsilon_{\xi}^{0}$, the strain exponent $m_{\xi}$ and the flow stress $\sigma_{\xi}^{\mathrm{F}}$ are introduced as material parameters. From this, the effective plastic strain is given by the localization relation $\overline{\boldsymbol{\varepsilon}}_{\mathrm{p}}=\sum_{\xi} c_{\xi} \mathbb{B}_{\xi}^{T_{\mathrm{H}}}\left[\boldsymbol{\varepsilon}_{\mathrm{p} \xi}\right]$. The material parameters for the mean-field modeling of the duplex stainless steel $\mathrm{X} 2 \mathrm{CrNiN} 23-4$, listed in Table 3, are chosen based on the experimental results of Simon et al. [11]. Note that for simplicity the phase-specific behavior is modeled statistically isotropic. The blank sheet's initial residual stress state has been analysed using X-ray diffraction and the strain gauge hole drilling method at several positions on the sheet surface. Only minor residual stresses $|\sigma|<30 \mathrm{MPa}$ were obtained. Therefore, the initial residual stress state was not further considered in the simulation of the deep drawing process.

\section{Results and discussion}

When presenting and discussing the results, the first step is to present the global macro and phase-specific micro residual stress distribution exclusively for the drawing depth $d=40 \mathrm{~mm}$ by using stress contour plots. In the following sub-chapter, insight into the local effective and phasespecific micro residual stress distributions is given for the region of the cup frame. Finally, the influence of the drawing depth is discussed on basis of the macro residual stress distributions.

\subsection{Global macro and phase-specific micro residual stress distributions for $d=\mathbf{4 0} \mathrm{mm}$}

The simulation approach for global prediction of macro and phase-specific micro residual stress was applied for simulation of three drawing depths, as described in Fig. 3. Exemplary, the global residual stress distribution for the maximum investigated drawing depth $d=40 \mathrm{~mm}$ is presented in Fig. 5 for the circumferential direction (CD) by $\bar{\sigma}^{c}$ on the left and for the drawing direction (DD) by $\bar{\sigma}^{d}$ on the right. For both residual stress components it can be seen that the highest compressive residual stress develops at the inner surface of the cup's wall. Whereas in $\mathrm{CD}$ a maximum 
a

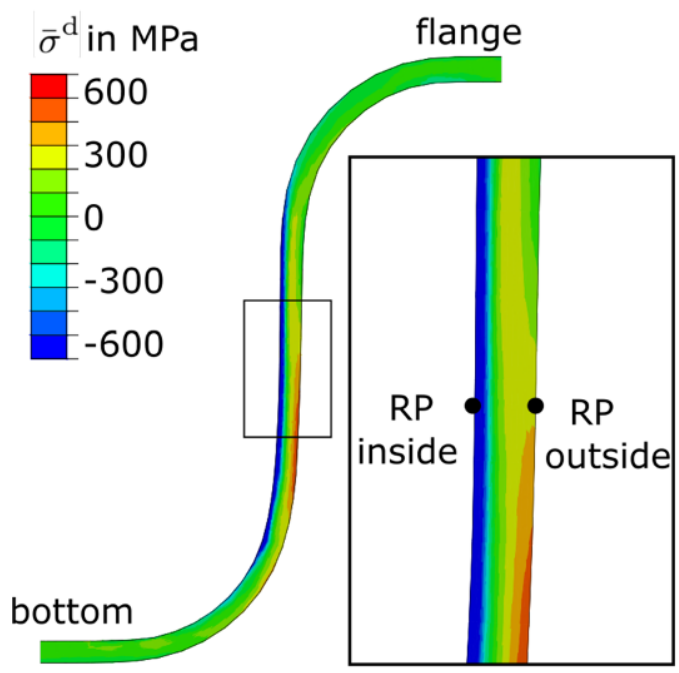

b

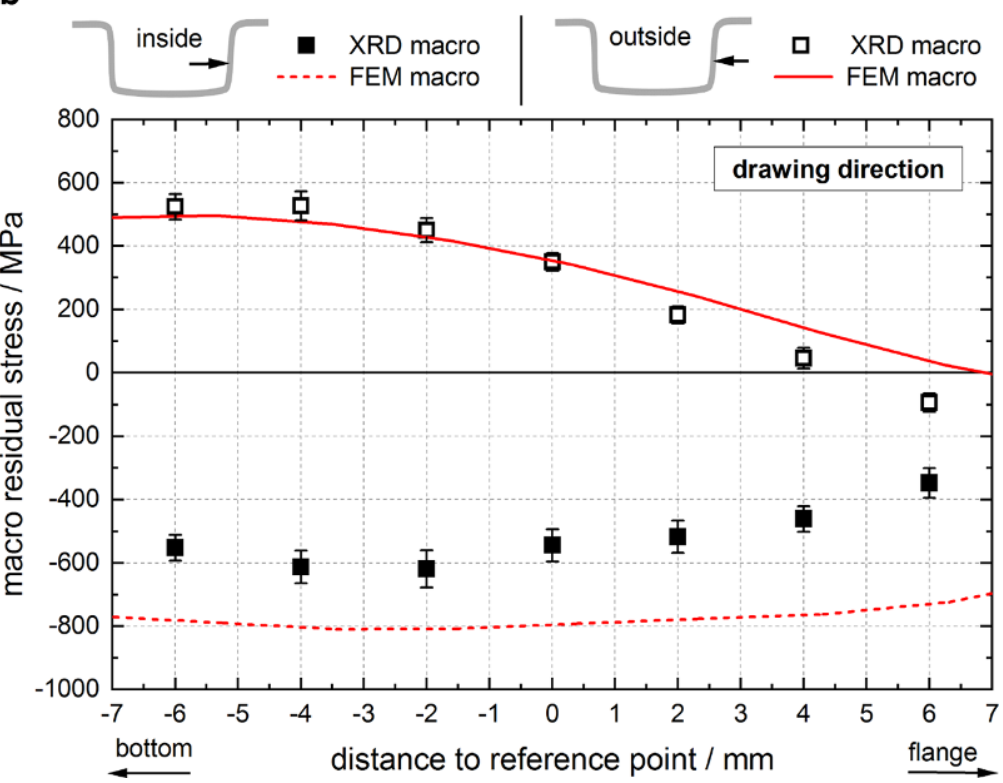

Fig. 8 Macro residual stress distribution in drawing direction (index 'd') at the cup's wall for $d=40 \mathrm{~mm}$ : FEM results (left) and validation with $\mathrm{XRD}$ results (right). At the contour plot the location of the reference point RP is given; the enlarged image section corresponds to a height of 14 $\mathrm{mm}$

compressive residual stress distribution of about $-500 \mathrm{MPa}$ is located close to the inner bottom radius, the compressive residual stress component in DD of about $-800 \mathrm{MPa}$ is almost homogeneously distributed over the entire height of the cup's inside wall. For the DD, the maximum of the balancing tensile residual stresses of approx. $500 \mathrm{MPa}$ is located at the outer wall surface in the transition area to the bottom radius. Although, in CD tensile residual stresses of up to $300 \mathrm{MPa}$ are also observed at the outside wall, the maximum in tensile residual stress $(500 \mathrm{MPa})$ here is located at the transition area from flange radius to the flange.
Generally, it is apparent that no significant macro residual stresses develop in the cup's bottom and flange areas.

In addition to the macro residual stress, Fig. 6 depicts the phase-specific micro residual stresses that superimpose with the macro residual stresses. The top left figure and bottom left figure show the respective micro residual stress distribution in CD for austenite $\sigma_{\gamma}^{c}$ and ferrite $\sigma_{\alpha}^{c}$. It can be seen that micro residual stresses developed in the cup's wall and flange, but not in the cup's bottom. Austenite shows compressive micro residual stresses of up to about $-100 \mathrm{MPa}$, which is compensated by tensile micro residual stresses in

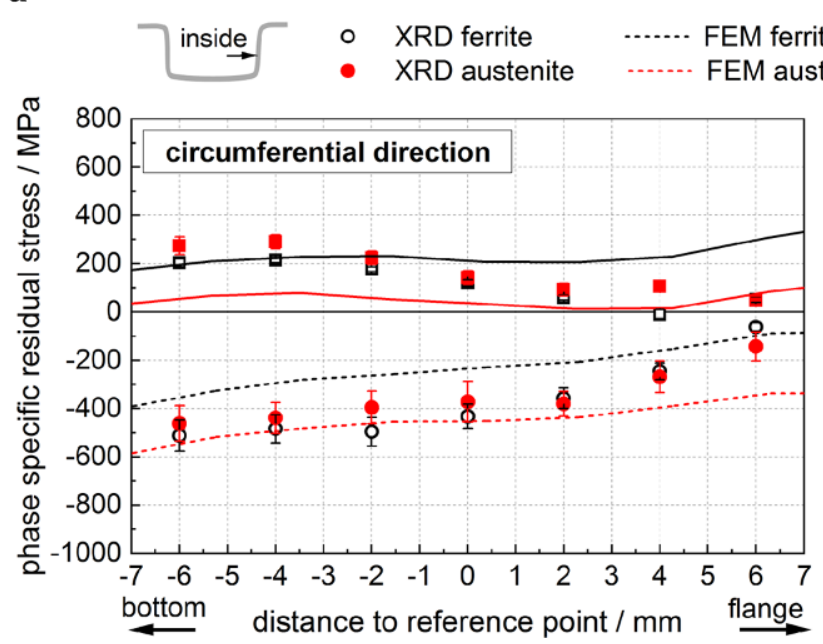

b
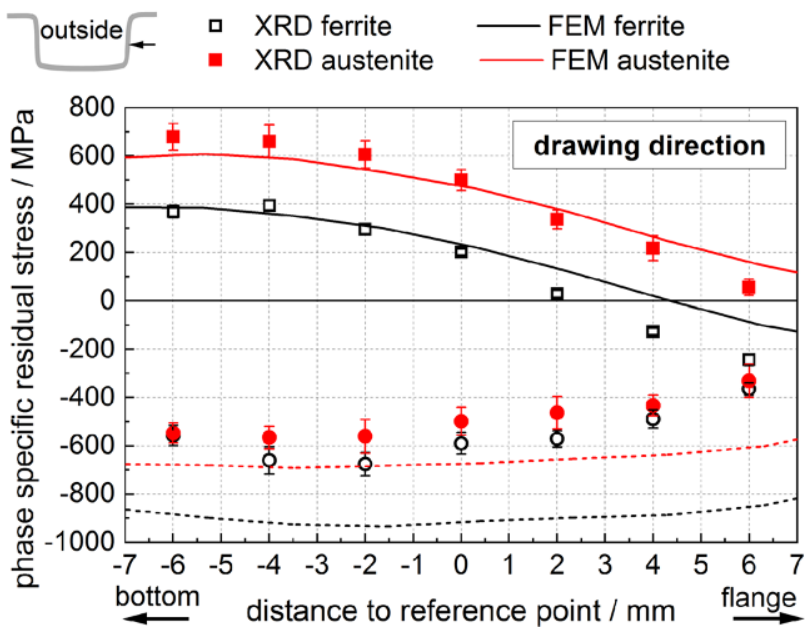

Fig. 9 Phase-specific residual stress distribution in circumferential direction (left) and drawing direction (right) at the cup's wall for $d=40 \mathrm{~mm}$ : comparison of FEM and XRD 

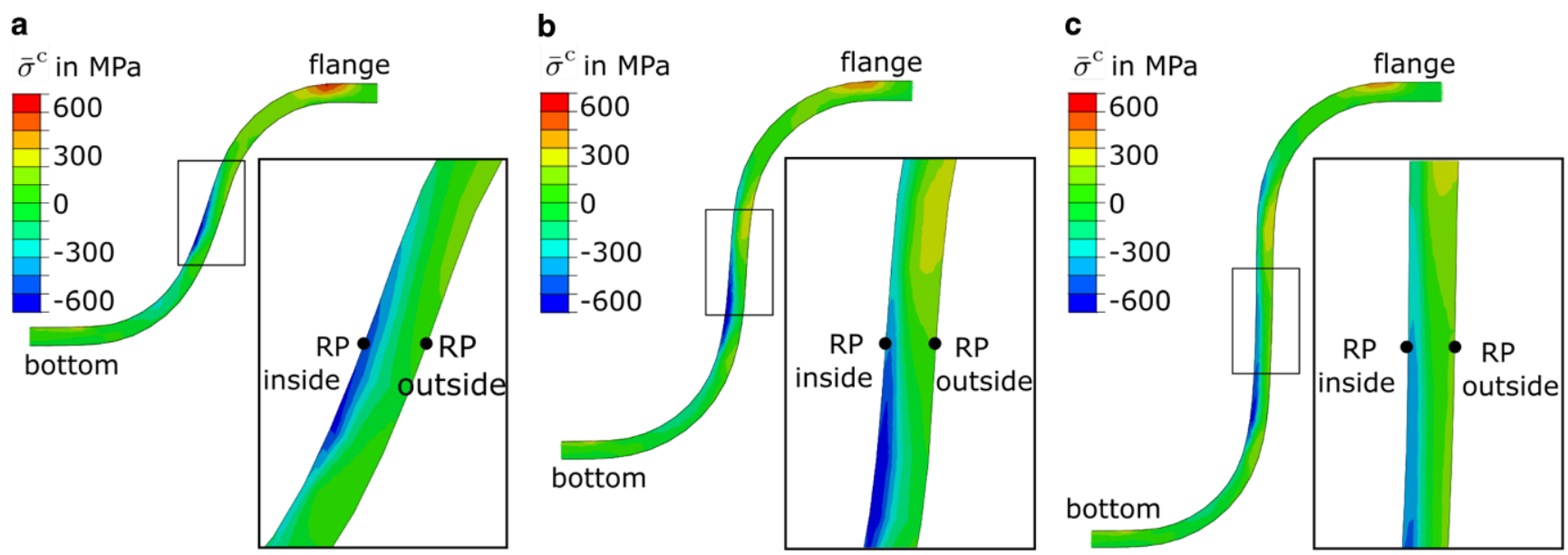

Fig. 10 Residual stress distribution in circumferential direction (index 'c') for drawing depths of $d=20 \mathrm{~mm}($ left $), d=30 \mathrm{~mm}($ centre $)$ and $d=40 \mathrm{~mm}($ right $)$

the ferrite phase of maximum $100 \mathrm{MPa}$ in magnitude. In contrast, the micro residual stress component in drawing direction $\sigma_{\gamma}^{d}$ (top right) and $\sigma_{\gamma}^{d}$ (bottom right) shows tensile residual stress in the austenite phase and compressive residual stress in the ferrite phase. It can be noted that for both directions the micro residual stresses do not exceed $\pm 100 \mathrm{MPa}$ and the cup's bottom is almost free of macro and phase-specific micro residual stress. Furthermore, no significant variance in macro and phase-specific micro residual stress distributions over the circumference is observable.

\subsection{Validation of local macro and micro residual stress distribution for $d=\mathbf{4 0} \mathrm{mm}$}

For validation of the numerical findings the above presented results are now compared to residual stress distributions at the inner and outer wall experimentally determined using XRD. In Fig. 7 the numerical macro residual stresses for the circumferential direction are presented, together with experimentally determined macro residual stresses, calculated from phase-specific residual stresses according to Fig. 1. On the left hand side, a cross section of the simulated macro residual stresses $\bar{\sigma}^{c}$ with a detailed view of the cup's wall at half height is shown. In the diagram on the right hand side the numerical results are compared to XRD results determined in $\mathrm{CD}$ at the inner and outer wall for seven measuring points vertically distributed over a length of $12 \mathrm{~mm}$. The results indicate that the lateral residual stress gradient is accurately predicted by the FEM approach. Both, the course of the tensile residual stresses at the outside wall and the compressive residual stress gradient at the inner wall are in very good agreement with the experimental results.

In Fig. 8 an equivalent presentation of the numerical and experimental results for the macro residual stresses now in drawing direction is given. Here, the lateral gradient of the predominant tensile residual stresses at the outside wall is well predicted by the simulation, including the transition to compressive residual stresses in direction of the flange. However, the experimentally determined compressive residual stresses at the inside wall of approx. $-350 \mathrm{MPa}$ to $-600 \mathrm{MPa}$ are overestimated by the simulation of about $-200 \mathrm{MPa}$, but the qualitative course is well predicted. Generally, the numerically determined macro residual stresses are in good agreement with the XRD results.

In the following, the numerically predicted phase-specific residual stresses, i.e. macro residual stresses superimposed with the phase-specific micro residual stresses, are validated by the phase-specific residual stresses, experimentally determined by X-ray diffraction. A comparison of the circumferential direction is given in Fig. 9 on the left hand side, the drawing direction is depicted in Fig. 9 on the right hand side. The experimental results show that for the investigated areas at the inside and outside wall both phase-specific residual stresses, i.e. the phase-specific residual stresses in ferrite and in austenite, follow the course of the macro residual stress. In consequence, this means that for the respective residual stress component the phase-specific micro residual stresses are homogeneous in magnitude. Although calculation and measurement regarding the phasespecific residual stresses in DD at the outside wall are in very good agreement, micro residual stresses on the inside wall are overestimated by approx. 50MPa. Nevertheless, it is evident that the numerical approach is well suited for the qualitative and quantitative prediction of macro and phasespecific micro residual stresses on a component level. 
a

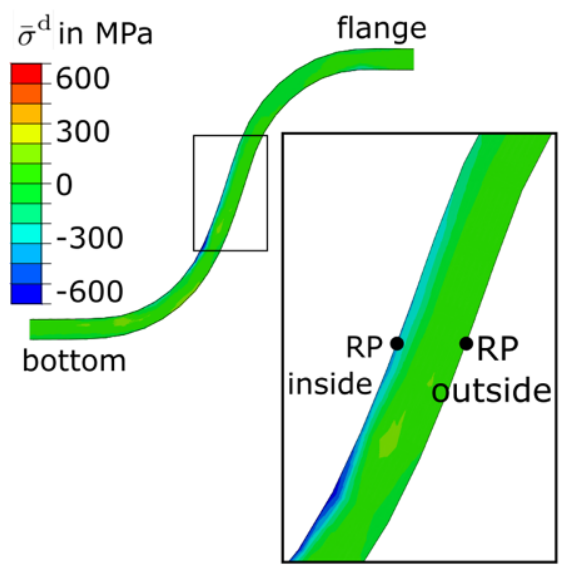

b

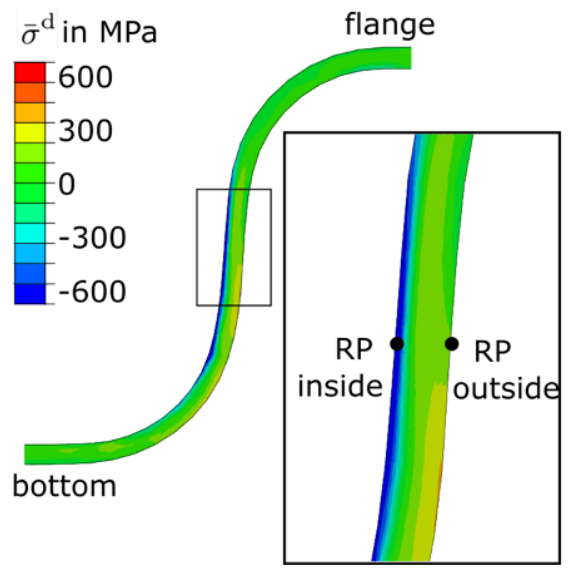

C

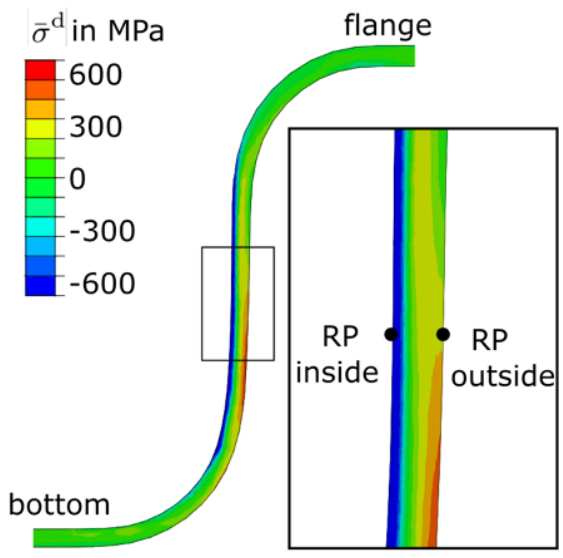

Fig. 11 Residual stress distribution in drawing direction (index 'd') for drawing depths of $d=20 \mathrm{~mm}$ (left), $d=30 \mathrm{~mm}$ (centre) and $d=40 \mathrm{~mm}$ (right)

\subsection{Influence of the drawing depth $d$ on the macro residual stresses}

The above described results regarding the $40 \mathrm{~mm}$ deep drawn cup show that only minor micro residual stresses developed for the investigated duplex stainless steel compared to the magnitude of the macro residual stress. For reasons of clarity, the influence of the drawing depth in the following is discussed based solely on the macro residual stress evolution. Since the residual stress maxima are predominantly located at the cup's wall, again the residual stress distribution is discussed for this section in detail. Fig. 10 depicts a cross sectional view of the macro residual stress distribution in circumferential direction with increasing drawing depth $d$ from left to right. For all three drawing depths, the significant compressive residual stress distribution is located at the inner wall in the transition zone to the bottom radius. Those residual stresses are balanced by tensile residual stresses at the outer wall, increasing in magnitude towards the flange.

The corresponding evolution of the residual stress component in drawing direction is given in Fig. 11. Analogous to the $\mathrm{CD}$, the compressive residual stress maximum is located at the inside wall near the bottom radius, which is increasing in magnitude with drawing depth $d$. It can be observed that the highest level of tensile residual stress lies almost at the same height of the opposite side of the cup's wall.

The gradient of the residual stresses over the sheet thickness is a result of the inhomogeneous material flow at the a

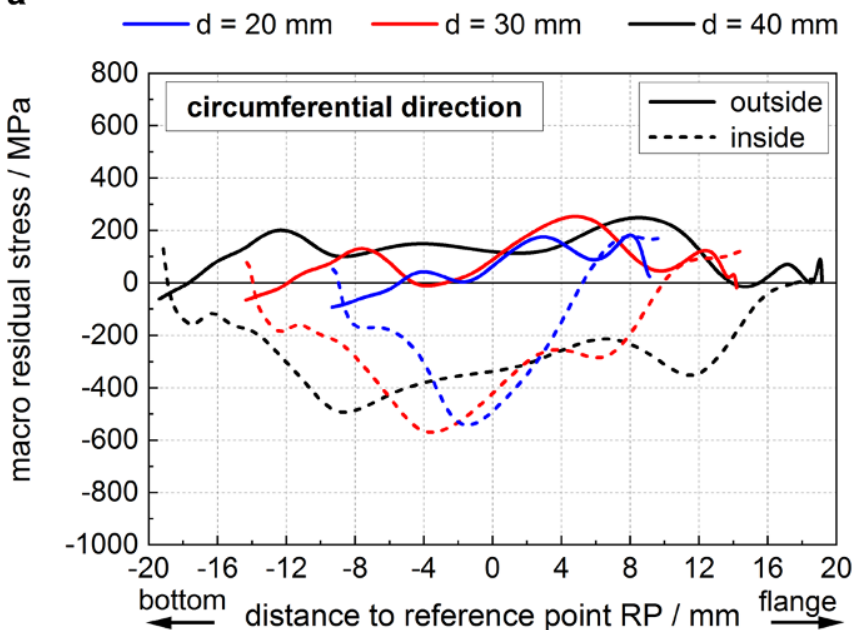

b

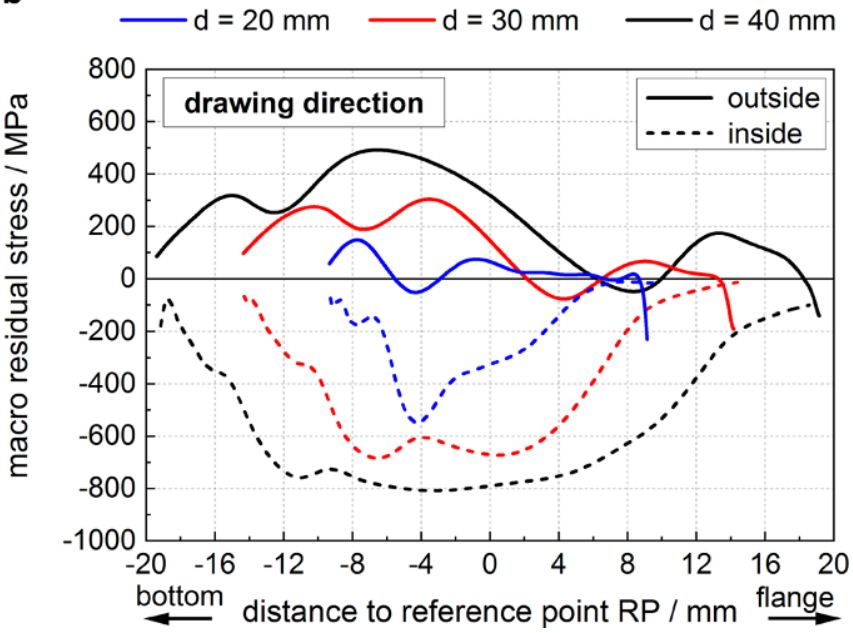

Fig. 12 Macro residual stress distribution at the inside and the outside surface of the cup's wall and transition radii for circumferential direction (left) and drawing direction (right) according to the FEM simulations for $d=40 \mathrm{~mm}, d=30 \mathrm{~mm}$ and $d=20 \mathrm{~mm}$. Respective reference points RD are located at half height on the cups' wall 
punch and the die radius already at the beginning of the forming process. A further increase of the drawing depth shifts the maxima away from the reference point at the cup's half height, accompanied by a noticeable sheet thinning (not separately displayed here) of the cup's wall. In Fig. 12 the course of the macro residual stress at the inner and outer wall is depicted for the residual stress component in circumferential direction (left) and drawing direction (right) for all investigated drawing depths in detail. Here, it can be observed that for $\mathrm{CD}$ the tensile and compressive residual stress maxima are shifted but nearly constant in magnitude. Furthermore, it is noticeable that the regions with tensile residual stress on the outside and compressive residual stress on the inside are also shifted towards larger distances to the reference point in the regions at the cup's half height with increasing drawing depth $d$, which means that the regions showing compressive residual stress (inside) and tensile residual stress (outside) are extended with increasing drawing depths, respectively. This behaviour is identical for the residual stress distributions of the drawing direction (right). However, in contrast to the circumferential direction, the residual stress component in drawing direction increases significantly in magnitude with increasing drawing depth. Furthermore, the local residual stress maxima at the inner wall surface are extended to a more homogeneous residual stress field over the cup's wall, which has been confirmed by the experimental results, presented in Fig. 8 .

\section{Conclusion}

In this work, the evolution of the residual stress distributions in deep-drawn circular cups made of duplex stainless steel X2CrNiN23-4 is investigated regarding different drawing depths. A two-scale numerical simulation approach was applied to calculate the macro and phase-specific micro residual stresses for ferrite and austenite in every integration point of the entire component. For this purpose, the phase-specific strain hardening of the particular material state is considered. The numerical results are compared to phase-specific residual stresses experimentally determined by means of X-ray diffraction at the surface of an accordingly deep-drawn cup.

From the numerical and experimental findings the following conclusions can be drawn regarding the numerical prediction of macro and phase-specific micro residual stresses:

- The calculated macro residual stress distributions are in very good agreement with near-surface XRD analysis at the inner and outer surfaces of the cup's wall, indicating that the chosen numerical simulation approach is well- suited for the prediction of the effective residual stresses at the component level.

- Compared to the macro residual stress level, only minor phase-specific micro residual stresses of maximum $\pm 100 \mathrm{MPa}$ develop, being almost homogeneous in regions of comparable degree of plastic deformation. However, according to these experimental findings, the phasespecific micro residual stresses are slightly overestimated by the numerical simulations.

- Apart of this slight overestimation, the first time applied phase-specific input data is well suited for the prediction of phase-specific residual stresses for the deep-drawn duplex stainless steel.

- The rather low phase-specific residual stresses determined experimentally and numerically prove that the strain hardening behaviour of the two phases ferrite and austenite is very similar for the investigated state of the duplex stainless steel X2CrNiN23-4.

Furthermore, the influence of the drawing depth on the macro residual stress distribution for the investigated deep drawing process can be summarized as follows:

- Significant residual stresses develop in the near-surface area of the inner and outer walls as well as in the transition zone to the bottom and flange radius. In contrast, bottom and flange remain almost free of process induced residual stresses, as expected.

- At the cup's inner wall high compressive residual stresses were obtained, with significantly higher residual stresses in drawing direction compared to the circumferential direction.

- At the outside wall predominantly tensile residual stresses occur for both, drawing and circumferential direction.

- With increasing drawing depth, the tensile and compressive residual stresses, which are acting in drawing direction, increase significantly, whereas the circumferential residual stresses remain constant in magnitude.

- Moreover, the regions with high residual stress at the cup's frame are more extensive for larger drawing depths.

Planned experiments under cyclic loading conditions will provide the foundation for determining the necessary material parameters to account for backstress effects in order to further improve the numerical approach.

Acknowledgements This research was funded by the German Research Foundation (DFG) within the Priority Programme SPP2013 "Targeted Use of Forming Induced Residual Stresses in Metal Components" (Gi 376/13-2, Bo 1466/14-2, LI 1556/61-2). The support by the German Research Foundation (DFG) is gratefully acknowledged.

Author Contributions Conceptualization, J.G., N.S., H.E., S.W.; methodology, H.E., N.S., S.W.; software, H.E.; validation, N.S.; formal analysis, J.G., N.S., H.E.,S.W.; investigation, N.S., H.E., S.W.; resources, J.G., T.B., M.L.; writing—original draft preparation, N.S., 
H.E., S.W.; writing-review and editing, N.S., H.E., S.W., J.G., T.B., M.L.; visualization, N.S., H.E.; supervision, J.G.; project administration, J.G., T.B., M.L.; funding acquisition, J.G., T.B., M.L. All authors have read and agreed to the published version of the manuscript.

Funding Open Access funding enabled and organized by Projekt DEAL.

\section{Conflict of interest}

The authors declare that they have no conflict of interest.

Open Access This article is licensed under a Creative Commons Attribution 4.0 International License, which permits use, sharing, adaptation, distribution and reproduction in any medium or format, as long as you give appropriate credit to the original author(s) and the source, provide a link to the Creative Commons licence, and indicate if changes were made. The images or other third party material in this article are included in the article's Creative Commons licence, unless indicated otherwise in a credit line to the material. If material is not included in the article's Creative Commons licence and your intended use is not permitted by statutory regulation or exceeds the permitted use, you will need to obtain permission directly from the copyright holder. To view a copy of this licence, visit http://creativecommons.org/licenses/by/4. $0 /$.

\section{References}

1. Zein H, El Sherbiny M, Abd-Rabou M et al (2014) Thinning and spring back prediction of sheet metal in the deep drawing process. Mater Des 53:797-808. https://doi.org/10.1016/j.matdes.2013.07. 078

2. Lee MG, Kim D, Kim C, Wenner ML, Chung K (2005) Springback evaluation of automotive sheets based on isotropic--kinematic hardening laws and non-quadratic anisotropic yield functions, part III: applications. Int J Plast 21(5):915-953. https://doi.org/10.1007/ s12540-011-0212-2

3. Carden W, Geng L, Matlock D, Wagoner R (2002) Measurement of springback. Int J Mech Sci 44(1):79-101. https://doi.org/10.1016/ S0020-7403(01)00082-0
4. Gnaeupel-Herold T, Prask HJ, Fields RJ, Foecke TJ, Xia ZC, Lienert U (2004) A synchrotron study of residual stresses in a Al6022 deep drawn cup. Mater Sci Eng A 366(1):104-113. https:// doi.org/10.1016/j.msea.2003.08.059

5. Danckert J (1995) Reduction of the residual stresses in a deepdrawn cup by modifying the draw die profile. CIRP Ann 43(1):259262. https://doi.org/10.1016/S0007-8506(07)62321-X

6. El Sherbiny M, Zein H, Abd-Rabou M et al (2014) Thinning and residual stresses of sheet metal in the deep drawing process. Mater Des 55:869. https://doi.org/10.1016/j.matdes.2013.10.055

7. Behnken H, Hauk V (1992) On the influence of micro-residual stresses during cyclic loading. In: 3 rd European Conference on Residual Stresses, pp 733-742

8. Kanouté P, Boso D, Chaboche J, Schrefler B (2009) Multiscale methods for composites: A review. Arch Comput Methods Eng 16(1):31-75. https://doi.org/10.1007/s11831-008-9028-8

9. Simon N, Erdle H, Walzer S, Gibmeier J, Böhlke T, Liewald M (2019) Phase-specific residual stresses induced by deep drawing of lean duplex steel: measurement vs. simulation. Prod Eng 13(2):227-237. https://doi.org/10.1007/s11740-019-00877-4

10. Hofinger J, Erdle H, Böhlke T (2020) Prediction of residual stresses of second kind in deep drawing using an incremental two-scale material model. Philos Mag 100(22):2836-2856. https://doi.org/10. 1080/14786435.2020.1798533

11. Simon N, Krause M, Heinemann P, Erdle H, Böhlke T, Gibmeier J (2020) Phase-Specific Strain Hardening and Load Partitioning of Cold Rolled Duplex Stainless Steel X2CrNiN23-4. Crystals 10(11):976. https://doi.org/10.1007/s00419-021-01931-3

12. Siegert K (2015) Blechumformung: Verfahren, Werkzeuge und Maschinen. Springer, Berlin Heidelberg

13. Doege E, Behrens BA (2016) Blechumformung. Springer, Berlin, Heidelberg, pp 251-454. https://doi.org/10.1007/978-3-662-438916_3

14. Macherauch E, Müller P (1961) Das $\sin ^{2} \psi$-Verfahren der röntgenographischen Spannungsmessung. Z Angew Phys 13:305-312

15. Wolfstieg U (1976) Die Symmetrisierung unsymmetrischer Interferenzlinien mit Hilfe von Spezialblenden. HTM 31(1/2):23

16. Hauk V, Nikolin HJ (1988) The evaluation of the distribution of residual stresses of the I. kind (RS I) and of the II. kind (RS II) in textured materials. Textures Microstruct 8:693-716. https://doi.org/ 10.1155/TSM.8-9.693 